\title{
Dominación, sexualidad masculina y prostitución en España: ¿por qué los hombres españoles consumen sexo de pago?
}

\author{
Domination, masculine sexuality and prostitution in Spain: why do Spanish \\ men consume paid sex?
}

\author{
Águeda Gómez-Suárez / agueda@uvigo.es \\ Silvia Pérez-Freire / silviapf@uvigo.es \\ Universidad de Vigo, España \\ Rosa Ma Verdugo-Matés / rosa.verdugo@usc.es \\ Universidad de Santiago de Compostela, España
}

\begin{abstract}
This paper studies focuses on clients of prostitution in Spain in order to understand why these men pay for sex. We analyzed the narratives of users clients of prostitution through in-depth semi-directed interviews, group interviews, and discussion groups. This material is given structure by the application of the theory of frame analysis. We obtained four ideal client types of clients were obtained, namely: misogynist (hatred of women), consumerist (everything is for sale), friend (affectionate but abusive), and critic (ocasional and repentant). We reach the conclusion that From this point of view the purchase of sex has nothing to do with is not due to the searching for quality sex, fun and hedonistic pleasure, but rather it is a strategy to that reinforces a masculine identity that conforms molded by to the expectations of the peer group.
\end{abstract}

Key words: gender, users clients of prostitution, frame analysis, theories of masculinity.

Resumen: Este artículo se centra en el estudio de los clientes de prostitución en España, con el propósito de entender por qué los hombres acuden al sexo de pago. Para responder a esta interrogante, se analizaron los discursos de los hombres consumidores de prostitución mediante entrevistas en profundidad semidirigidas, entrevistas grupales y grupos de discusión. Con el fin de estructurar coherentemente las narraciones obtenidas y clasificarlas en categorías se aplicó el marco teórico del "frame analysis". Se obtuvieron cuatro tipos ideales de cliente: misógino (odio a la mujer); consumista (todo se compra y vende); amigo (afectivo aunque abusa); y crítico (ocasional y arrepentido). Desde nuestra perspectiva, la compra de sexo de pago no se produce por la búsqueda de sexo de calidad, diversión y disfrute hedonista, sino que es una estrategia de refuerzo de una masculinidad conformada por una identidad que gira en torno a la exhibición frente al grupo de pares.

Palabras clave: género, clientes de prostitución, frame analysis, teorías de la masculinidad. 


\section{Introducción}

Durante décadas el debate en torno a la prostitución se ha centrado en la cuestión filosófico-política del consentimiento. Por un lado, están los que defienden la normalización de la industria del sexo argumentando que prostituirse es un derecho de la mujer; por el otro, se sitúan quienes sostienen que es irracional e injusto argumentar seriamente en torno al consentimiento en un planeta globalizado y atravesado por las desigualdades económicas, étnicas y, muy especialmente, de género. ${ }^{1}$

Para Sheila Jeffreys (2011), la utilización del término "trabajadoras sexuales" invisibiliza a los hombres y sitúa a las prostitutas como la causa de la existencia de la prostitución. Además, dicha terminología otorga a la prostitución la consideración de "un trabajo como otro cualquiera", enviando un mensaje muy claro a la sociedad: la prostitución no tiene género, cualquiera puede prostituirse (Miguel, 2012). Por ello Jeffreys propone utilizar el término "mujer prostituida" para indicar que la prostituta no existe sin el otro polo de la relación, al que denomina prostituyente o prostituidor frente a la denominación de "cliente", más propia de la industria y los empresarios del sexo.

La prostitución se ha legitimado desde posturas conservadoras, liberales y progresistas, pero también encontramos en todas estas ideologías personas que se han opuesto a la misma. Los argumentos conservadores se han basado en lo que se denomina la doble moral sexual: las mujeres no deben tener relaciones sexuales hasta el matrimonio, mientras que los hombres deben tenerlas. Se da por hecho que los hombres necesitan, y es bueno que tengan, relaciones sexuales variadas. Desde la perspectiva conservadora la prostitución se considera "un mal menor". El "mal mayor" sería que los hombres no pudieran tener sus necesidades sexuales satisfechas (Miguel, 2012).

En los años sesenta, la llegada de la revolución sexual pondrá fin a una parte de la hipocresía que suponía la doble moral sexual. Según las nuevas normas sexuales tener muchas relaciones sexuales es bueno, moderno y transgresor. Ahora bien, la revolución sexual fue crítica con la doble moral pero no con la sexualidad tradicional masculina, de forma que se comienza a idealizar la figura del putero (Miguel, 2012). Una de las claves de la reconceptualización de la prostitución a partir de los sesenta fue la teoría de la libre elección y el consentimiento: si hay consentimiento, la libertad individual aparece

1 Este estudio parte de la convicción de que actualmente la prostitución es un fenómeno generizado, es decir, totalmente atravesado por el género, ya que es un hecho que la mayoría de las personas que se prostituyen son mujeres, mientras que la práctica totalidad de los demandantes de prostitución son hombres. 

masculina y prostitución en España: ¿por qué los hombres españoles consumen sexo de pago?

como un factor determinante para su aceptación. Las consecuencias de la revolución sexual fueron, en este caso concreto, similares a las de la doble moral tradicional: el mercado de prostitutas quedaba asegurado, reforzado y ampliado.

Actualmente, el patriarcado neoliberal ${ }^{2}$ ha extremado la violencia de género contra las mujeres, a través de su deshumanización y cosificación, convertidas en mercancía que se pueden transformar en nuevos nichos de negocios. La nueva función de la prostitución en este momento histórico neoliberal es reforzar la sensación de poder y dominio que debe acompañar a la masculinidad hegemónica mediante el uso misógino de la sexualidad.

La prostitución ya no esta ahí para satisfacer sexualmente al hombre, sino para que ellos puedan disponer de un espacio/cuerpo/territorio donde poder ejercer un determinado tipo de masculinidad, en un momento de "pánico sexual masculino" o "vértigo de género" (Atencio, 2015). La prostitución es una institución que sirve al mantenimiento del orden de género porque sirve a los hombres para apuntalar su masculinidad tradicional (naturalizada, no penetrable y dominante) y para extraer de ella o de su existencia un capital simbólico masculino, una especie de plusvalía de género frente a las mujeres (Connell, 2003).

Hoy en día, en España podemos diferenciar varias tipologías discursivas en torno a este fenómeno. En un extremo se situarían las abolicionistas o antiprostitución, y en el otro las pro-legalización o pro-prostitución (Gómez et al., 2015). El discurso abolicionista parte de que la prostitución es una expresión más de la violencia de género, en el que las víctimas son mayoritariamente mujeres en un contexto patriarcal y capitalista que mercantiliza y cosifica a la mujer. Por ende, los clientes son cómplices de esta explotación sexual y se aprovechan de este privilegio patriarcal propio de su género. Según esta visión, es necesario distinguir analíticamente el fenómeno social, que es la prostitución, del colectivo concreto que son las mujeres que la ejercen. Esta distinción permitirá criticar la realidad social y la estructura de subordinación y explotación sexual que subyace de la prostitución y tener una posición de solidaridad con las víctimas de ese sistema (Cobo, 2014).

2 El "patriarcado neoliberal" es un término referido al momento histórico actual por el que atraviesan las sociedades occidentales, caracterizado por la permanencia de un modelo de dominación masculina concreto, en un contexto de capitalismo neoliberal. Ambas lógicas se combinan en el mundo de la prostitución contemporánea: es un fenómeno generizado, atravesado por lógicas consumistas (compro lo que se vende). Otros autores hablan de pornocapitalismo (Sáez et al., 2015) para enfatizar la cultura sexual dominante emanada de los relatos pornográficos mainstreams, en un contexto capitalista. 
Un factor relevante para comprender esta práctica social es la desigualdad económica entre la población que se prostituye y la población demandante, promoviendo el surgimiento de una nueva clase de servidumbre, donde la prostitución pasa a ser una de las pocas salidas disponibles para las mujeres pobres (Sassen, 2003).

Carole Pateman (1988) conceptualiza la prostitución teniendo en cuenta que está generizada (los sexos no tienen el mismo papel). Se trataría de una institución por la que la sociedad regula el libre acceso de los hombres al cuerpo de las mujeres por un precio. Y ha sido y es tolerada derivada de la legitimación de una ideología patriarcal, y ahora también neoliberal (Jeffreys, 2011). La normalización de la prostitución, según el filósofo Scott A. Anderson (2002), conllevaría que las personas (mujeres, sobre todo) acabaran perdiendo el derecho a la autonomía sexual.

La tipología discursiva pro-legalización mantiene una postura amoral respecto a la prostitución: ni es mala en sí misma, ni atenta contra la mujer, sino que se trata de un trabajo más, tan digno como otro cualquiera. Este discurso se sitúa en la lucha contra la estigmatización y marginación tanto de las mujeres en prostitución como de los clientes, contra la trata sexual, explotación y abuso en el marco de los derechos de todo trabajador y en el uso del empoderamiento del ejercicio de ciudadanía.

Desde esta tipología discursiva se proponen medidas más complejas que tengan como objetivo un cambio de mentalidad en la cultura socioafectiva hegemónica en nuestra sociedad, con el fin de terminar con cualquier relación de poder, dominación y explotación en las interacciones afectivo-sexuales. En esta línea se encuadran filósofas como Martha Nussbaum (1999), quien sostiene que los problemas que pueda acarrear el realizar trabajo sexual proceden de factores coyunturales como el estigma social que rodea a la misma.

Con este texto pretendemos contribuir al debate en torno al fenómeno de la prostitución en nuestro país, analizando un aspecto de esta realidad que no ha sido tratado suficientemente: los demandantes de prostitución o clientes. ${ }^{3}$ Dada la complejidad del propio concepto de prostitución y las dificultades metodológicas para su cuantificación, es difícil proporcionar cifras exactas que nos ayuden a conocer la magnitud real del fenómeno. En el caso español, en un informe del año 2007 elaborado por la Comisión Mixta de los Derechos de la Mujer y de la Igualdad de Oportunidades del Congreso de

3 El "cliente" es el actor principal que ejerce el papel activo y el que tiene la responsabilidad primigenia en la existencia y permanencia del fenómeno, por lo que debería denominarse "prostituidor". Sin embargo, en este texto utilizaremos la acepción mercantilista de "cliente" por ser la más normalizada. 
los Diputados del Gobierno de España, se indica que existen unas 300.000 mujeres que ejercen la prostitución, siendo la abrumadora mayoría pobres, inmigrantes e indocumentadas, mientras que casi la totalidad de los clientes, el 99,7\%, son hombres.

Además, en ese informe se estima que el negocio de la prostitución en España genera unos 18.000 millones de euros anuales y que el gasto de los españoles en prostitución se sitúa en los 50 millones de euros al día. Evidentemente, este destacado gasto en servicios de prostitución está asociado a un también elevado número de consumidores, tal y como se desprende de otra encuesta realizada por el Centro de Investigaciones Sociológicas en el año 2009 , que estima que un $32,1 \%$ de los hombres han pagado alguna vez por mantener relaciones sexuales.

En este artículo presentamos los resultados más relevantes de una investigación que desarrollamos durante el periodo 2011-2013. ${ }^{4}$ Dividimos la exposición en cuatro apartados: en el primero, se hace un recorrido por los estudios llevados a cabo sobre esta temática; en el segundo, se exponen las bases teóricas y metodológicas; en el tercero - epicentro de este trabajo- se aborda el estudio de la narraciones de los clientes; finalmente, en el último apartado, se presentan los resultados alcanzados y se reflexiona sobre los mismos.

\section{Precursores de las investigaciones sobre clientes de prostitución}

Las investigaciones que analizan - y en algunos casos clasifican - al cliente de prostitución son relativamente recientes. A nivel internacional, el autor pionero en esta temática es Sven-Axel Manson (2001), quien estudió el fenómeno de la prostitución a partir de la década de 1970, desde el punto de vistade los hombres y el clientelismo. En su libro Men'spracticesinprostitution: the case of Sweden, divide en cuatro grupos a los clientes de prostitución; el primero está formado por hombres que alimentan la fantasía de la "puta guarra"; el segundo lo conforman los que quieren experimentar formas de actividad sexual no habituales; en el tercer grupo se encuentran quienes por miedo, timidez, edad avanzada o minusvalía acuden a la prostitución como un consolador; por último, el cuarto grupo está constituido principalmente por jóvenes que tienen una visión de lo sexual definida por la pornografía, la publicidad y los programas de ocio.

Otra destacada investigación en la que se realiza una tipología de los clientes de prostitución es la efectuada en Francia por el Mouvement du Nid.

4 Proyecto "Consumo de prostitución en España: clientes y mujeres" (COMPECLIMU). Exp. Núm. 2/10, (2011-2013). Instituto de la Mujer. Investigadora Principal: A.G.S. 
Los estudios, dirigidos por Saíd Bouamama y Claudine Legardinier (2006), se concretarán en el libro Les clients de la prostitution, l'enquête, donde se identifican cinco tipos de clientes.

En la primera tipología, que engloba al $75 \%$ de los casos, se encuadran los hombres que justifican su condición de "prostituidores" como un derivado de sus propias insuficiencias sexuales, sociales y afectivas. La segunda tipología reúne a los hombres que apelan a la desconfianza, el temor y el odio que les inspiran las mujeres para justificar este consumo. La tercera categoría incluye a los "consumidores de mercancías", que se acogen a su condición de "consumidores" para "comprar" aquello que se "vende". La cuarta categoría engloba a los que desean cumplir un imperativo de la sexualidad, de forma que pagan para ahorrarse problemas. Por último, la quinta tipología aglutina a aquellos hombres adictos al sexo.

Sin embargo, la mayoría de las investigaciones que analizan los motivos que alegan los hombres para demandar este tipo de servicio no elaboran una tipología de los mismos. Así, Anne Allison (1994) analizó el consumo de prostitución en los clubs de Japón por parte de los hombres de negocios en el libro Nightwork: Sexuality, Pleasure, and Corporate Masculinity in a Tokyo Hostess Club. Una de sus conclusiones es que el consumo de prostitución es más bien un ritual de pertenencia al grupo masculino, utilizado como ocio organizado entre el grupo de pares (salidas nocturnas, reuniones de trabajo, despedidas de soltero, etcétera). Allison afirma que muchos hombres se sienten coaccionados por el grupo, por lo que el consumo de prostitución funciona como una forma de control del género masculino, para demostrar ante el grupo de pares que son "totalmente hombres".

Una perspectiva diferente aparece en Sex Markets, en el que Giusta, Di Tommaso y Strom (2008) exploran la oferta y demanda de prostitución y concluyen que la mayoría de los hombres que utilizan estos servicios se sienten excitados por la idea de lo ilícito, de la transgresión: para ellos la mujer se prostituye por gusto, no por dinero.

La sociabilidad, la necesidad de dominación y la diversión son algunos de los motivos que sobresalen en otros estudios. La sociabilidad como motivo del cliente de prostitución se recoge en la investigación realizada en Brasil por Elisiane Pasini (2000), donde se habla del hombre "habitual" para definir al cliente de prostitución.

La necesidad de dominación se destaca en un trabajo sobre los clientes finlandeses publicado por Anne-Maria Marttila (2003), donde se relaciona la demanda de sexo de pago con las estructuras de poder generalizadas y con la necesidad de dominación. La diversión y el deseo de experimentar otras 
Águeda Gómez-Suárez, Silvia Pérez-Freire y Rosa Ma Verdugo-Matés. Dominación, sexualidad masculina y prostitución en España: ¿por qué los hombres españoles consumen sexo de pago?

experiencias sexuales está presente en el libro de Melissa Farley, Julie Bindel y Jacqueline M. Golding (2009) titulado Men who buy sex. Who they buy and what they know. A partir de 103 entrevistas a clientes de prostitución en Inglaterra, el 54\% de los encuestados afirmó que el motivo principal de consumir sexo de pago respondía sobre todo a recibir satisfacción inmediata, de entretenimiento y placer, así como "variar de mujeres".

En España, el primer trabajo que analiza al cliente de prostitución es de José L. Solana (2002), quien en 2002 publica el artículo "Prostitución de mujeres inmigrantes en la provincia de Córdoba", donde distingue dos tipos de clientes: los objetualizadores y los personalizadores. Posteriormente, en el año 2003, Ma José Barahona y Luís M. García publican el libro Una aproximación al perfil del cliente de prostitución femenina en la Comunidad de Madrid. A partir de 15 entrevistas a clientes españoles extrajeron los motivos para pagar por servicios sexuales: insatisfacción de las relaciones con sus parejas; mayor frecuencia y variedad de relaciones sexuales; poder derivado del hecho de pagar servicios sexuales; satisfacer fantasías sexuales; y por último, búsqueda de diversión. (Barahona y García, 2003).

Rafael López y David Baringo publican en el año 2007 el artículo "Ciudad y prostitución heterosexual en España: el punto de vista del 'cliente' masculino". A partir de la realización de 12 entrevistas a diferentes hombres consumidores, establecen seis categorías: hombres a los que les costaba relacionarse con mujeres; varones que salían en grupo para divertirse; hombres casados que deseaban tener relaciones extramaritales como infidelidad menor; varones que tenían crisis de pareja; hombres que acudían por cuestiones derivadas de su ámbito laboral o de negocios; y por último, varones jóvenes que alegaban menor complicación y esfuerzo (López y Baringo, 2007).

En 2010, Ma José Barahona publica el libro Estudio sobre la información, opinión y actitud de los habitantes de Alava ante el fenómeno de la prostitución y una aproximación al perfil del cliente de prostitución femenina. La investigación se llevó a cabo mediante la realización de 452 cuestionarios distribuidos en Álava a mayores de 18 años. Un 16,6\% de los varones que participaron en la encuesta admitieron que habían pagado por sexo en algún momento de su vida. Además, un 30\% de los encuestados no respondieron a esta pregunta, lo cual lleva a pensar a la autora del estudio que también pagaron pero no lo quieren reconocer (Barahona, 2010).

También en el año 2010, Carmen Meneses analiza los motivos que tienen los hombres para pagar por sexo. A partir de 138 entrevistas, de las 14 razones para pagar por sexo, las tres con las que los clientes estaban en mayor acuerdo fueron: poder elegir a distintas mujeres (56,5\%), pensar que el sexo 
de pago genera menos problemas $(46,6 \%)$ y tener sexo rápido e impersonal $(41,3 \%)$. Con las motivaciones ofrecidas por los clientes, Meneses aplica un análisis factorial con el método de Extracción de Componentes Principales y obtiene seis factores que explicaban el 80\% de la varianza: "compañía", "necesidad", "distracción", "riesgo", "dominar” y "rapidez" (Meneses, 2010).

En 2012, Enrique J. Díez publica el artículo "El papel de los hombres en la prostitución...", donde afirma que cada vez son más los hombres que buscan prostitutas para dominarlas: los hombres han experimentado una pérdida de poder y de masculinidad tradicional, y no consiguen crear relaciones de reciprocidad y respeto hacia las mujeres (Díez, 2012).

Gómez y Pérez publican en 2009 el libro Prostitución: clientes e outros homes, que trata sobre los jóvenes y el consumo de prostitución en Galicia. En ese trabajo se realizaron 17 entrevistas a clientes, 5 entrevistas a grupos de discusión de colectivos masculinizados, ${ }^{5} 6$ entrevistas a mujeres en prostitución, 2 entrevistas a transexuales en prostitución, 3 a dueños y gerentes de clubes de alterne, 1 a un trabajador de un club y 3 a técnicos de servicios sociales que trabajan con mujeres en prostitución (Gómez y Pérez, 2009).

Tal y como se desprende de las diferentes investigaciones que hemos analizado, el consumo de sexo de pago por parte de los varones se deriva de una forma concreta de entender el "ser hombre". Si en el pasado los valores tradicionales del varón eran la paternidad responsable y el rol de protector y proveedor de la familia, hoy en día la virilidad se construye a través de una "compulsiva vida sexual" que se presume delante del grupo de pares masculinos.

\section{Consideraciones teóricas y metodológicas}

Para desarrollar este trabajo, y con el fin de entender a nuestros sujetos de estudio, fue necesario reflexionar sobre la construcción de la masculinidad. El género es uno de los portadores de los mecanismos centrales mediante los cuales el poder y los recursos son distribuidos en una sociedad, y es a través de ellos como los individuos modelan los significados de sus vidas. Los estudios de género analizan las relaciones asimétricas de poder y oportunidad que cada individuo tiene en la sociedad en función de su cuerpo sexual (Ortner, 1979). Cada grupo social exalta un modelo de masculinidad por encima de los demás, que responde a lógicas políticas, económicas, sociales y culturales.

5 Estudiantes de ciclo formativo de electricidad, informática y secundaria; sindicalistas del metal y médicos. 
En cualquier caso, la construcción de la identidad social masculina se relaciona con el sistema sexo-género de una sociedad (Otegui, 1999). Este sistema estaría basado, en primer lugar, en las teorías que investigan la "naturalización” por las que se explican las características sexuales socialmente construidas (Irigaray, 1998; Moore y Gillette, 1993; Chodorow, 1989; Gilligan, 1982; Goldberg, 1973); en segundo lugar, en las teorías funcionalistas que surgen como legitimadoras de los órdenes sociosexuales hegemónicos en las sociedades occidentales (Parsons, 1999; Gilmore, 1990); y en tercer lugar, en las teorías que enfatizan la existencia de una diversidad en la cual el componente relacional de las mismas las sitúan en "procesos socio-históricos de hegemonización de unas específicas relaciones de poder" (Otegui, 1999), tales como las teorías constructivistas (Connell, 2003; Bourdieu, 2000) y las teorías queer (Preciado, 2002; Butler, 2001).

En definitiva, la importancia de los estudios de masculinidad radica en su capacidad para analizar las prácticas y representaciones de los varones desde sus especificidades de género, siendo dichas prácticas parte de unas relaciones sociales que colocan a los hombres mayoritariamente en una posición de dominación. La identidad masculina no responde actualmente a un modelo común, sino a una construcción colectiva configurada previamente en las instituciones y se ejerce a través de las prácticas sociales.

El consumo de prostitución viene a resaltar estas características, en donde en un mismo contexto cultural conviven distintos modelos de masculinidad que operan con mandatos de género diferenciados y en donde la sexualidad es una expresión del ejercicio de dominación y poder sobre los cuerpos de las mujeres en nuestra sociedad. Debido a la heterogeneidad del perfil sociológico de los clientes, en este trabajo se optó por clasificar a los mismos en función del "relato" elaborado en relación con su experiencia y percepción en torno al fenómeno de la prostitución.

Para analizar sus narraciones se optó por aplicar el marco teórico del "frame analysis" (Gerhards, 1995; Goffman, 1974), con el fin de estructurar coherentemente sus relatos y clasificarlos en categorías para mejorar su manejo y comprensión. Este método de investigación es actualmente muy utilizado para analizar cómo las personas entienden las situaciones y actividades desde múltiples disciplinas. Con este tipo de análisis se propone identificar la lógica interna de los "marcos interpretativos" dominantes, poniendo énfasis en las diversas representaciones que realizan los actores sociales, mediante un principio de organización que transforma la información fragmentaria en un problema político estructurado y significativo. Por lo tanto, los marcos son construcciones que dan significado a dicha realidad y estructuran la comprensión de la misma (Snow et al., 1993; Tarrow, 1997). 
En el siguiente apartado se describen las dimensiones de enmarcamiento centrales en el discurso ideológico de los clientes de prostitución en nuestro país, y en sus proclamas legitimadoras de objetivos, intereses e ideologías, a partir de las declaraciones extraídas en las entrevistas individuales y grupales realizadas a los mismos. Para ello se aplicaron entrevistas en profundidad semidirigidas a 29 clientes, ${ }^{6} 13$ mujeres en prostitución, ${ }^{7} 3$ dueños de clubes y/o pisos, 4 trabajadores de clubes y/o pisos y 23 técnicos sociales, académicas y/o profesionales de los servicios sociales; además, se llevaron a cabo tres entrevistas grupales a grupos de hombres en nueve comunidades autónomas españolas. Nuestro objetivo es establecer una tipología de clientes de prostitución a partir del análisis de sus discursos, lo que diferencia esta investigación de otras que nos anteceden.

\section{Discursos de clientes}

En este epígrafe clasificamos a los clientes de prostitución a partir de sus discursos, mediante su análisis a través del "frame analysis" (Goffman, 1974). El resultado fue la identificación de cuatro tipos de clientes a los que hemos denominado "cliente misógino", "cliente consumidor", "cliente amigo" y "cliente crítico" (véase Figura $1^{8}$ ). El perfil sociológico de los clientes de prostitución que hemos analizado es muy amplio y hetereogéneo, respecto a la edad, estado civil, formación y/o profesión (véase Cuadro 1); por lo tanto, la clasificación resultante de esta investigación se podría extrapolar al conjunto de clientes de prostitución.

6 Las muestras científicas estructurales en la investigación cualitativa se eligen mediante criterios de representación socioestructural. La representatividad de la técnica estructural no se sustenta en la probabilidad de elegir una muestra proporcional, sino de carácter representativo. En este caso, para seleccionar a las personas entrevistadas, se optó por la estrategia de "bola de nieve" (García Ferrando et al., 2000).

7 La mayoría de las mujeres que ejercen la prostitución en España son extranjeras en situación irregular, y en función de su nacionalidad, poseen percepciones diferentes de los clientes: las subsaharianas no ven al cliente como un "ser humano", sino más bien como un "otro"; las latinoamericanas los consideran maleducados, sucios y groseros; las rumanas los consideran menos machistas que sus paisanos. Finalmente, entre las pocas españolas que se prostituyen, las de "toda la vida" generan amistad o confianza con ellos, y las que ejercen como efecto de la actual crisis económica, los rechazan y critican (Gómez y Pérez, 2009).

8 La figura y el cuadro se encuentran en el Anexo, al final del presente texto (Nota del editor). 
Águeda Gómez-Suárez, Silvia Pérez-Freire y Rosa Ma Verdugo-Matés. Dominación, sexualidad masculina y prostitución en España: ¿por qué los hombres españoles consumen sexo de pago?

\section{a. Cliente misógino}

En este grupo encontramos hombres de todas las edades y situaciones sentimentales. Ninguno de ellos tiene estudios superiores y todos desempeñan trabajos asociados a salarios bajos. En relación con su ideología no hemos encontrado a ninguno que se defina como de centro o de izquierdas. Para los clientes misóginos la existencia de servicios de prostitución es algo normal y necesario. No observan ninguna "zona oscura" en este negocio, adoptan una actitud totalmente acrítica e irreflexiva y naturalizan la existencia de la prostitución al considerarla consustancial a la humanidad:

E: ¿Cuál es tu opinión sobre la prostitución? C: Me parecen que prestan un servicio necesario a la sociedad y más demandado de lo que alguna gente quiere admitir (camarero, 21 años, soltero, Ourense, 2012).

Comparten la percepción de que todas las mujeres son "putas", pues en sus acciones y relaciones afectivo-sexuales ellas tienen siempre un interés económico y material. Su imaginario en torno al "mundo femenino" está cargado de connotaciones negativas sobre la mujer: la consideran un ser perverso, falso y materialista.

Yo creo que cuando una mujer va al sexo, va... buscando algo, ¡siempre!: matrimonio o... dinero, o contraprestaciones,... (militar, 56 años, divorciado - nulidad matrimonialZaragoza, 2011).

La imagen que tienen de la prostitución resulta muy banal. Pagan servicios de prostitución porque ésta es la única forma de poder conseguir una relación sexual con una mujer. Se ven a sí mismos como víctimas de un sistema en el que la ambición materialista de las mujeres les obliga a gastar su dinero. Señalan, irónicamente, que la prostitución es más económica que el matrimonio:

E: ¿Entonces para ti el sexo es casi todo de pago?, ¿más o menos? C: Sí, yo creo que sí, lo que pasa es que el del matrimonio sale más caro que el otro (militar, 56 años, divorciado -nulidad matrimonial-, Zaragoza, 2011).

Algunos hombres siempre han querido imaginar que las prostitutas son libres para escogerlos a ellos y para sentir verdadero placer con ellos. Es una fantasía sexual que crean y mantienen para reforzar su propia masculinidad hegemónica. Esta idea les sirve para erotizar la práctica de la prostitución ${ }^{9}$ :

9 El imaginario sexual masculino se refiere a la visión ideal que pauta el comportamiento masculino deseable y se construye así: los hombres no pagan por un orgasmo, pagan por una fantasía de masculinidad que incluye una supuesta e ilimitada capacidad para proporcionar placer a todas las mujeres (Gimeno, 2012). 
Ellas disfrutan y algunas están ahí porque quieren... a mí me gusta ir por las "formas de seducción" que allí se desarrollan, que se despliegan... ellas disfrutan "dando placer" porque "dar placer es un placer" y también que hay algo espiritual, trascendental en esa relación: no siempre, pero sí ocurre a veces (profesor de secundaria, 56 años, casado, Madrid, 2012).

Para este perfil de cliente las mujeres se prostituyen porque quieren, porque realizan un trabajo cómodo con el que ganan mucho dinero y sin grandes esfuerzos:

Si folla ${ }^{10}$ es por dinero, está más claro que el agua (...). Yo estoy seguro que muchas de las prostitutas que hay las ponen mañana a fregar a 900 euros el mes, no van a fregar (...) (militar, 56 años, divorciado - nulidad matrimonial-, Zaragoza, 2011).

Si los clientes misóginos perciben a las mujeres como seres materialistas, consideran que los hombres son, en cambio, "seres sexuados", promiscuos genéticamente. Apelan a ciertas teorías pseudocientíficas para demostrar esta inevitable tendencia de los varones a la sexualidad:

Yo creo mucho en la teoría de... este amigo mío... de Darwin, de Charles Darwin, entonces yo creo que el hombre tiene cierta predisposición genética a la procreación, a la procreación, entonces, estoy seguro que el hombre, en definitiva, aparte de tener una sensación de placer, él genéticamente está predispuesto al sexo... (militar, 56 años, divorciado - nulidad matrimonial-, Zaragoza, 2011).

Entre las motivaciones más señaladas por los clientes misóginos destacan la búsqueda de "sexo de calidad", cambiar la rutina de la vida en pareja y satisfacer necesidades fisiológicas para mantener la salud corporal y el equilibrio mental:

¡Placer! (tajante) (...) falta de amor... falta de sexo... alguna vez cuando no tenía chica, cuando era más joven, je, je, quería pasarlo bien e iba allá... ahora pues hago más para cambiar... porque si no siempre con la misma... pues te cansa (obrero, estudios primarios, 28 años, casado, Ourense, 2012).

Otro motivo que arguyen para justificar su consumo es la percepción de que muchas mujeres no son tan activas sexualmente como ellos:

Yo soy incapaz pero yo tengo amigos, compañeros que están todo el día aquí metidos y... y lo decimos, es el típico macho español, tiene mujer, tiene queridas, se va de putas, o sea, quiero decir, no podemos... no podemos encasillar... hay mujeres que (...) son muy mojigatas y que no... no les gusta el sexo (médico, 40 años aprox., divorciado, Zaragoza, 2011).

Las experiencias sexuales con mujeres de otras nacionalidades otorga a estas relaciones un valor añadido, estableciendo una categoría de las culturas afectivo-sexuales:

10 "Follar" es el término utilizado frecuentemente en España que equivale a "coger" en México. 
Águeda Gómez-Suárez, Silvia Pérez-Freire y Rosa Ma Verdugo-Matés. Dominación, sexualidad masculina y prostitución en España: ¿por qué los hombres españoles consumen sexo de pago?

Las mujeres sudamericanas normalmente son más ardientes, por ejemplo, que las mujeres del Este, mucho más ardientes, brasileñas, colombianas, mucho más ardientes, por su cultura o por su manera de pensar, ¿no? (militar, 56 años, divorciado - nulidad matrimonial-, Zaragoza, 2011).

Como ocurrirá en los otros perfiles de clientes, el consumo de sexo con el grupo de colegas o amigos es lo más frecuente y, en muchos casos, está dentro del "protocolo" de las propias relaciones laborales con los clientes o con los compañeros de trabajo:

E: ¿Es muy habitual entonces en el trabajo acabar en un club? C: ¡Yo creo que sí! Yo lo que... ¡el 70\% de la gente! je! E: Y tú ¿ por qué crees que pasa eso? C: (...) Te juntas tres, uno podemos trabajar en una cosa, otro en otra y otro en otra y ya el $90 \%$ de la gente dice: ¿no hay por aquí algún club ? pues sí, hay uno ahí, pues vamos a tomar algo, no sé qué... (comercial de maquinaria agrícola, 25 años, soltero, Ponferrada, 2012).

$\mathrm{Su}$ actitud acrítica y conformista frente a la prostitución desemboca en una apuesta por la legalización y regularización de esta actividad:

Ya que ellas están ahí, por lo menos que tengan derecho a seguridad social y esas historias (obrero, estudios primarios, 28 años, casado, Ourense, 2012).

Reconocen la existencia de explotación sexual y abusos pero no la valoran. También constatan la connivencia policial (sobornos y "carta blanca": sexo gratis). Piensan que con la legalización estas prácticas se terminarían:

Yo estoy convencido de que hay... buahhh! si tiraras de ese hilooo... te ibas a quedar asustada, es que ellas tienen miedo, no van a decir, este tampoco te lo va a decir (por el dueño del piso) pero estoy seguro de que este... (...) si estuviera legalizado, terminao el tema (militar, 56 años, divorciado — nulidad matrimonial—, Zaragoza, 2011).

Los clientes de este perfil adoptan una postura sexista y contraria a las políticas de igualdad de género, llegando a manifestar una actitud incrédula frente a los casos de violencia machista contra las mujeres:

[En relación con la igualdad de género] Yo creo que es una película que montaron los gobiernos de izquierda para generar unos puestos de tra..., puestos de recreo, que en realidad nunca podremos ser iguales, porque dos cosas iguales son las que no se distingue, y un hombre y una mujer se distinguen perfectamente (...). Yo creo que lo del maltrato es otra película también que están montando... (hostelero, estudios secundarios, 53 años, soltero, Ourense, 2012).

Los clientes misóginos ven en la prostitución el ámbito donde pueden seguir manteniendo su posición de poder masculina que, según ellos, se ha visto erosionada por las políticas de igualdad:

[Sobre la prostitución] (...) Algo que venden y nosotros lo compramos (...) pero es como una relación de poder, es decir, yo pago y por tanto haces lo que yo quiera, ¿no? (...) (profesor artes marciales, 50 años, divorciado con pareja, A Coruña, 2011). 


\section{b. Cliente consumidor}

En nuestra investigación hemos obtenido un discurso de lugares comunes hegemónico entre los jóvenes, un discurso de carácter explícitamente no sexista y crítico con la herencia machista del pasado. Dentro de este grupo predominan los menores de 40 años. Todos ellos tienen estudios secundarios o universitarios.

En relación con su ideología, ninguno su identifica con la derecha. Se trata de jóvenes, en general, formados e informados, que comparten una ética hedonista de consumo y que mayoritariamente tienen una base material débil y dependiente, pues la mayoría de ellos viven con sus familias. Consideran que hoy en día se goza de más libertad en todo tipo de relaciones, incluidas las sexuales. Opinan que se está diluyendo el tópico de que las mujeres sólo buscan afecto y los hombres solo buscan sexo; para ellos, ambos sexos buscan lo mismo:

Siempre ese es el prejuicio: que los hombres siempre van a por eso, o sea, por sexo, y las mujeres a por lo afectivo, pero yo pienso que eso no es más que un prejuicio, la verdad (GD2, estudiantes de Economía, Córdoba, 2011).

Ven a la mujer como una igual. En su opinión, ambos sexos son activos en todos los ámbitos (social, laboral y sexual), aunque reconocen que las mujeres aún siguen sufriendo cierta discriminación y desigualdad:

La verdad es que creo que las cosas están mucho mejor que hace unos años, aunque podemos encontrar algunas diferencias, sobre todo en el terreno laboral; en el resto, en la sexualidad o en la sociedad creo que ya apenas hay diferencias (administrativo, formación profesional, 29 años, soltero con pareja, Ourense, 2012).

Sin embargo, reconocen que aún se sanciona más la libertad sexual de las mujeres que de los hombres, algo que consideran injusto:

Sí, eso sí sigue ahí presente: que el hombre que liga mucho es un campeón, y la mujer que se acuesta con muchos tíos ${ }^{11}$ es una puta. Y no sé cuánto tardarán en quitarlo, pero sí es muy injusto (GD2, estudiantes de Economía, Córdoba, 2011).

El cliente consumidor intuye la existencia de mujeres explotadas sexualmente, situación que resuelve desde la perspectiva consumista, "comprando lo que se vende":

La mayoría (de las mujeres en prostitución) creo que están explotadas (...) ellas estarán en una situación que no creo que si les dieran a elegir quisieran hacer eso (...) pero no, no lo veo tampoco mal (funcionario, maestro, 35 años, soltero, Ourense, 2012).

11 "Tíos" es el término utilizado frecuentemente en España que equivale a "hombres" en México. 
Águeda Gómez-Suárez, Silvia Pérez-Freire y Rosa Ma Verdugo-Matés. Dominación, sexualidad masculina y prostitución en España: ¿por qué los hombres españoles consumen sexo de pago?

En algunos clientes de este grupo se aprecia una defensa de la igualdad de género, lo que los lleva a criticar actitudes machistas de otros hombres. Sin embargo, sus libertades y sus derechos como consumidores están por encima de otro tipo de consideraciones de carácter ético o ideológico:

Creo que debería haber igualdad de géneros, pero creo que actualmente no es algo que se pueda apreciar fácilmente en la sociedad (profesor de secundaria, 43 años, casado, Ourense, 2012).

Entre estos jóvenes se comparte una visión no sexista y menos machista que la que se observa en generaciones masculinas anteriores pero, paradójicamente, esta perspectiva sobre la igualdad de género no la aplican en el ámbito de la prostitución. En ellos se observa una postura contradictoria: buscan mujeres iguales como pareja...

La mujer ideal, lo del físico ya... ihombre! Tiene que gustarme físicamente pero... tiene que estar en sintonía con mis ideas... y con mi forma de ser, porque el físico, puede ser una belleza pero después (...) que pudieras hablar con ella de cualquier cosa y que no fuera un florero (funcionario, maestro, 35 años, soltero, Ourense, 2012).

...y a la par, a las mujeres en prostitución las tratan como mercancías, como un producto de consumo más, un consumo de MacSexo: rápido, frugal, de escasa calidad y sin compromiso. De esta forma consiguen conciliar las visiones no sexistas con la compra de sexo de pago: el ámbito de la prostitución es para ellos un mercado más de consumo.

Esta visión mercantilista se complementa con un sistema de valores en el que el hedonismo individualista y la búsqueda del placer se convierten en los motores de su vida:

[Práctica sexual] Normalmente era siempre lo mismo, ya hacían ellas su trabajo, son como profesionales, son como (...) porque ellas también hacen para que te entre el calentón (maestro, 35 años, soltero, Ourense, 2012).

Es bastante frecuente que el consumo de sexo se realice por cuestiones sociales, emulando al grupo de amigos. Esta última razón se relaciona con un tipo de subcultura masculina gremialista: es el grupo el que otorga tu identidad masculina (Connell, 2003): ${ }^{12}$

Yo llegaba allí [a los clubes] para estar con mis amigos (...) en una de las ocasiones ya sabía que en parte de la despedida de soltero había cosas relacionadas con la prostitución, pero yo no intervine en nada en cuanto al contacto con la mujer ni en cuanto a las cosas que podían o no suceder a lo largo de aquella noche (profesor de secundaria, 43 años, casado, Ourense, 2012).

12 Connell (2003) define la masculinidad como una posición en las relaciones de género. Para describir el proceso de construcción de las masculinidades, centra su análisis de las relaciones entre hombres, más que en la relación hombre-mujer. 
En muchos casos, estas prácticas grupales se realizan por primera vez como un rito de iniciación, para "hacerse hombres":

Ha sido en celebraciones grupales (...) supongo que íbamos por diversión (...) pero ¡vamos! Que por motivos sexuales yo no fui, algunos amigos míos supongo que sí, pero yo no; y por fantasía tampoco (...) ahora lo recuerdo como algo similar a un rito de iniciación (profesor de secundaria, 43 años, casado, Ourense, 2012).

En algunos de sus discursos surge una cierta autocrítica a su pasado como cliente: consumieron por "locuras de juventud":

Iríamos alrededor de una o dos veces al año (...) eso fue durante unos años, yo que sé, cuatro o cinco años... chorradas ${ }^{13}$ pre-adultas (risas) (profesor de secundaria, 43 años, casado, Ourense, 2012).

La unión de esta visión parcialmente no sexista y al mismo tiempo mercantilista-consumista desemboca en una posición a favor de la legalización de la prostitución, pues así se garantizaría la "calidad higiénica y sanitaria del producto" a comprar:

En una sociedad de mercado libre, esta actividad debiera estar regulada tanto para garantizar unas condiciones adecuadas del desarrollo de su actividad para ellas como para garantizar también unas condiciones mínimas de seguridad a los clientes en cuanto higiene y en cuanto a la seguridad material tanto de los clientes como de ellas mismas (gerente de una tienda de informática, 34 años, soltero, Ourense, 2012).

Dentro de la tipología del cliente consumidor hemos localizado un discurso minoritario con una visión más política, crítica, transparente, respetuosa, comprometedora y ética con el consumo de sexo de pago:

Yo nunca entré en un puticlub, en mi vida (...) y no, no tengo mucha curiosidad... aparte, me de la un poco de... eeeh... iré, el día, que sepa, que... las mujeres queee eeeh que están ahí, eeeh son mujeres libres que están ahí porque pagan un seguro y su derecho a estar (hostelero, 37 años, con pareja, Santiago de Compostela, 2012).

Su discurso hace referencia a una perspectiva de izquierdas, feminista y anticapitalista. Con la compra de sexo busca ampliar sus experiencias sensoriales, afectivas, eróticas, etc., desde un planteamiento complejo y sofisticado de la sexualidad. La sexualidad es entendida en un sentido amplio y pansexual, desde una perspectiva más orientalista que la propia de la matriz cultural judeocristiana o bio-médica occidental.

Yo no... pues, muchas veces me divertía pensar en un rol en el que yo mandara, y otras veces me... tenía una sensación eeeh!! superplacentera adoptando uno rol en el que una mujer me dominara, ¿no? Porque jugué a todo, jugué todos los papeles, entonces eeeh!! es sexo, entonces me... me lo paso bien... (hostelero, 37 años, con pareja, Santiago de Compostela, 2012).

13 "Chorradas" es el término utilizado frecuentemente en España que equivale a "tontería" en México. 
Águeda Gómez-Suárez, Silvia Pérez-Freire y Rosa Ma Verdugo-Matés. Dominación, sexualidad masculina y prostitución en España: ¿por qué los hombres españoles consumen sexo de pago?

Su compromiso ideológico y responsable lo lleva a criticar la bipolaridad de los medios de comunicación en relación con la prostitución: la mayoría de los periódicos publican noticias de violencia de género y, al mismo tiempo, anuncios de prostitución:

Sí sí... en el, yo creo que es increíble que se denuncie... que un mismo periódico... hay, honrosas excepciones... Público, por supuesto, iieeeh!! que es un periódico que no publicaaaa anuncios de prostitución (...) Perooo... pero bueno, iieeeh!! otros periódicos, comooo El Mundo o El País, me de la igual... eeh de repente hacen una denuncia... de violencia de género, y al mismo tiempo están la... probablemente financiando... (hostelero, 37 años, con pareja, Santiago de Compostela, 2012).

\section{c. Cliente amigo}

En este perfil predominan los hombres menores de 40 años. Están representados todos los niveles de estudio y todas las profesiones. Además, entre ellos existe un claro predominio de la ideología de izquierdas. En la tipología del cliente amigo se enmarcan aquellos hombres que adoptan una actitud "amable" cuando compran sexo de pago. Estos clientes son capaces de humanizar a las mujeres en prostitución y de "empatizar" con ellas. Para ellos las mujeres que se prostituyen lo hacen, mayoritariamente, por no tener otra alternativa.

Me da pena que haya mujeres que tengan que dedicarse a esto, aunque si lo hacen en general, es como último recurso y, desde luego, es mejor que robar (operario de RENFE, estudios primarios, 45 años, viudo, Ourense, 2011).

Piensan que su buen hacer como amantes los diferencia de otros clientes, porque ellos saben provocar el placer en las prostitutas. Se perciben a sí mismos como clientes de lujo, pues consiguen que las mujeres que se dedican a la prostitución disfruten con ellos, porque ellos las tratan bien y las hacen gozar. Esta actitud los lleva, en algunos casos, a establecer lazos afectivos que recrean los vínculos que surgen en las situaciones de "ligoteo casual" de fin de semana o de inicio de una relación amorosa:

A algunas les encantaba, incluso, bueno, lo típico, ¿̨no?, te daban el teléfono y "pues llámame un día y salimos" (...) y alguna incluso se enganchó un poco conmigo (profesor de Artes marciales, 50 años, divorciado con pareja, A Coruña, 2011).

En el contexto prostitucional existe una cierta "teatralización” por parte de las mujeres de un cortejo y de una relación sexual donde ellas hacen creer al cliente que él posee unas cualidades excepcionales que las hacen gozar y tener orgasmos, pero todo es fingido y teatralizado para que el cliente se sienta bien, como un "excelente amante". 
Aunque el cliente se lo cree y yo doy fe de ello por lo que tengo escuchado, y la mujer se está acostando con el cliente por dinero, no lo hace por afecto, ni por amor, ni siquiera por practicar sexo y a lo mejor le está dando muchísimo asco (entrevista técnica social, Proyecto Érguete Muller, Ourense, 2011).

Aunque las necesidades sexuales aparecen entre sus motivos, existen otros como cubrir aspectos más afectivos, la búsqueda de compañía o amistad:

Después de haber estado casado durante más de 20 años y sin haber tenido hijos, por una parte necesito sentir afecto, tengo ciertas necesidades afectivas y puedo cubrirlas, al menos temporalmente, de esta manera (operario de RENFE, estudios primarios, 45 años, viudo, Ourense, 2011).

Incluso a veces reconocen que consumir prostitución no es una decisión que los llene de orgullo. El cliente amigo suele argumentar que el consumo se produce en situaciones de reunión o de fiesta con amigos o compañeros de trabajo:

Fui, no consumí, tomar algo y no consumí, pero... (coge aire) pero esto es en temas de cenas... de de... de coger... vas a las cenas con unos amigos "vamos allí, vamos allí!" (...). Pero ir voy y tal, (...) pero no me gusta subir (desempleado, estudios secundarios, 47 años, divorciado, Barbadás, 2012).

Los clientes de este perfil suelen apoyar las posturas reglamentaristas respecto a la prostitución, aunque consideran que es difícil su regulación:

La regularización de esta actividad, incluyendo inspecciones médicas, reduciría la incidencia de estos efectos que pueden llegar, incluso, a afectar al seno familiar de aquellos hombres que acuden a estos servicios como consecuencia de la transmisión de enfermedades sexuales (médico, divorciado, Ourense, 2011).

\section{d. Cliente critico}

En este perfil predominan los hombres que tienen alrededor de 30 años, siendo lo más representativo de este grupo que todos se definen ideológicamente de izquierdas. El perfil narrativo del cliente crítico o arrepentido es el menos abundante entre los clientes entrevistados hasta el momento. En él aparece una óptica crítica, donde se reconoce la existencia de la desigualdad de géneros y las injusticias que sufren las mujeres en un entorno patriarcal y capitalista. Para ellos esta desigualdad se agrava a medida que descendemos en la escala socioeconómica, la procedencia y la situación legal de las mujeres en prostitución. Por ello este cliente considera que las mujeres prostituidas son uno de los colectivos sociales más vulnerables. Según ellos, las mujeres se prostituyen por necesitad, siendo en algunos casos víctimas de las mafias: 
Águeda Gómez-Suárez, Silvia Pérez-Freire y Rosa Ma Verdugo-Matés. Dominación, sexualidad masculina y prostitución en España: ¿por qué los hombres españoles consumen sexo de pago?

La prostitución es una realidad social que no fue afrontada nunca de la forma adecuada, porque es un problema, una situación, una realidad difícil. Es un trabajo muy complicado, no hay legislación, mueve mucho dinero, con mafias implicadas y algunas de estas mujeres están esclavizadas sufriendo agresiones, extorsiones, chantajes... (mediador de seguros, 48 años, casado, Ourense 2011).

El cliente crítico considera que existen más privilegios destinados a los hombres, y que además existe un mayor control de la vida emocional y sexual de las mujeres:

E: ¿Y la impresión que te dieron las mujeres que estaban allí ejerciendo? C: ¡Puffff!! De momento no lo pensé pero después sí que lo... iivaya vida de mierda!! Básicamente porque están allí esclavizadas, no por otra cosa, sí que me impresionó porque alguna tenía marcas en la cara, alguna cicatriz y tal (carpintero, 28 años, con pareja, A Pobra do Caramiñal, 2011).

Afirman que las motivaciones para consumir sexo de pago no son las que los hombres suelen indicar, sino que se esconden otras razones relacionadas con la situación de poder que poseen en el contexto prostitucional y que les permiten desahogar sus frustraciones cotidianas a través de la humillación y el abuso hacia estas mujeres:

Si te sientes como inferior y tal, tienes ahí una oportunidad para sentirte superior y para hacer lo que realmente quieras (...) subimos varios con varias, ya no me moló, ${ }^{14}$ porque noté un rollo como de superioridad (carpintero, 28 años, con pareja, A Pobra do Caramiñal, 2011).

Desarrollan una narrativa donde se apunta a otra de las motivaciones de los hombres que consumen sexo de pago: el incremento de la mercantilización de las relaciones humanas, que provoca que sexo y afecto se busquen, en muchos casos, de forma separada:

Buscas alguien que te haga una mamada por 15 euros, punto, se acabó... entonces la gente busca eso, esos cinco o diez minutos y el tío se desahogó (comercial, 50 años, casado, Santiago de Compostela, 2012).

\section{Conclusiones}

En las sociedades occidentales contemporáneas el consumo masivo de servicios de prostitución por parte de la población masculina es uno de los indicadores más significativos de una forma de entender, vivir y sentir la sexualidad, de vislumbrar la norma reguladora de los afectos y la sexualidad de nuestro momento histórico.

14 "Moló" es el término utilizado frecuentemente en España que equivale a "gustó" en México. 
Contrariamente a lo esperado, la prostitución ha adquirido una relevancia insospechada e impredecible en el contexto de liberalización sexual que hacía pensar en su paulatina desaparición. Decimos "insospechada" porque el compromiso con el valor de la igualdad, unido a la nueva libertad sexual que ya han disfrutado varias generaciones, generó la idea difusa de que la prostitución acabaría convirtiéndose en un fenómeno residual y marginal.

La prostitución se ha expandido y diversificado, volviéndose una actividad legitimada por el propio sistema poscapitalista, en un contexto de explotación y precarización cada vez más normalizado. A partir de un recorrido por toda la producción científica existente y también de la propia investigación empírica, este artículo sobre la prostitución en España se ha centrado en el estudio del cliente de la misma, tratando de entender por qué los hombres - el consumidor mayoritario de prostitución en nuestro país- acuden al sexo de pago.

Las tipologías que se obtuvieron en esta investigación poseen una elevada coincidencia con las de otros trabajos similares llevados a cabo en este campo. Sin embargo, en nuestra investigación hemos dado un paso más al llevar a cabo una caracterización de los clientes de cada tipología. En el perfil del cliente misógino predominan los hombres que tienen el nivel formativo bajo y se identifican con la ideología política de derechas. En el extremo contrario, los hombres del perfil del cliente crítico, destacan los que poseen un mayor nivel formativo y se autodefinen ideológicamente con la política de izquierdas.

Los individuos analizados desplegaron su perspectiva "emic" (visión propia de los sujetos investigados), particular sobre las razones, causas e impresiones en torno al consumo de prostitución, pero es desde la perspectiva "etic" (visión "desde fuera" de los sujetos investigados) desde donde se pueden complementar e interpretar en su total dimensión. A través de la perspectiva teórica empleada del "frame analysis" y de las significaciones sociológicas, se ha podido llegar a comprender esta realidad social.

En definitiva, esta investigación identifica una serie de causas sexuales y extrasexuales para consumir sexo de pago: la búsqueda de dominio, el entretenimiento, la afectividad, la sociabilidad, el deseo de consumir nuevas “mercancías”, etc. En ningún caso encontramos discursos de los amantes del placer por el placer como acto trascendente.

Las causas y los motivos son otros y, desde nuestro punto de vista, se relacionan con la construcción de una masculinidad dominante y patriarcal que aún sigue siendo hegemónica en nuestras sociedades, y que se vincula muy directamente con el vínculo homosocial (Gilmore, 1990; Connell, 2003): la relación con el grupo de pares masculinos (de ahí que, habitualmente, acudan al espacio prostitucional en grupo). 

masculina y prostitución en España: ¿por qué los hombres españoles consumen sexo de pago?

La compra de sexo de pago responde a un mandato patriarcal y a una estrategia, no necesariamente consciente, de reforzamiento de una masculinidad conformada por una identidad que gira en torno a la exhibición frente al grupo de pares, del "uso del falo" y de la práctica sexual frecuente con mujeres.

En nuestra hipótesis de trabajo se considera que la compra de servicios de prostitución está directamente relacionada con las masculinidades contemporáneas, construidas con base en la práctica sexual compulsiva y con los testigos de otros hombres para que conste públicamente ese apuntalamiento y reforzamiento de su masculinidad. La identidad masculina dominante se centra en un falocentrismo narcisista ${ }^{15}$ que desplaza al modelo tradicional (padre-protector-proveedor) y se construye en relación a los "otros" varones. $\mathrm{Y}$ en los espacios prostitutivos es donde se ampara, reproduce y legitima este tipo de identidad masculina.

Los elementos en los que se afianza esta dimensión son el consumo colectivo, el pacto de silencio compartido por los prostituidores y grupos de amigos - para que lo que ocurra dentro del club no trascienda- y la presenciauso del falo. Estos elementos originan un impecable código compartido por los sujetos virilizados, la "subcultura prostitutiva", que puede considerarse un exponente más de la violación de los derechos humanos y de la violencia de género.

La prostitución aparece como un elemento más de la industria de ocio en un momento sociohistórico de banalización de la sexualidad, de hipervaloración del placer y de mercantilización de las relaciones humanas (Han, 2014). Hay cuerpos, como los de algunas mujeres pobres, cuyo valor en el mercado laboral es casi nulo; sus cuerpos se maltratan y hasta asesinan, convertidos en marcas simbólicas del poder de una determinada masculinidad (Atencio, 2015): son las víctimas propiciatorias de los feminicidios, dentro de un contexto de capitalismo neoliberal.

Los efectos perversos y perniciosos del exceso de mercantilización y cosificación de los seres humanos estarían rechazados en otros modelos identitarios en los que se refuerzan otras formas de "masculinidad" basadas en el desarrollo personal integral, tanto en el ámbito físico, como psíquico y social de los hombres, a través del fomento de una vida sexual placentera y saludable, que se desarrolle en el marco de unas relaciones sociales respetuosas, igualitarias, justas y solidarias, tanto con los otros hombres como con las mujeres.

15 Con esta expresión nos referimos a una sexualidad misógina donde sólo importa el placer del hombre y se ignora a la mujer como sujeto, solamente se hace un uso instrumental de ella para "mayor gloria" del varón (Atencio et al., 2015). 
En nuestra opinión, en un mundo cada vez más globalizado, se hace necesario reflexionar sobre la sexualidad humana. Existen otras formas de interpretar el afecto, el género y la sexualidad para poder elaborar una "epistemología” alternativa que ayude a construir un mundo más justo e igualitario.

\section{Bibliografía}

Allison, Anne (1994), Nightwork: sexuality, pleasure and corporate masculinity in a Tokyo Hosstes Club, Chicago: University of Chicago Press.

Anderson, Scott A. (2002), "Sexual Autonomy. Making sense of the prohibition of Prostitution”, en Ethics, núm. 112, vol. 4, Chicago.

Atencio, Graciela [ed.] (2015), Feminicidio: el asesinato de mujeres por ser mujeres, Madrid: La Catarata.

Barahona Gomariz, Ma José (2010), Estudio sobre la información, opinión y actitud de los habitantes de Álava ante el fenómeno de la prostitución y una aproximación al perfil del cliente de prostitución femenina, Vitoria: Asociación Gizarterako.

Barahona Gomariz, Ma José y Luís Mariano García Vicente (2003), Una aproximación al perfil del cliente de prostitución femenina en la Comunidad de Madrid, Madrid: Publicaciones de la Dirección General de la Mujer.

Bouamama, Saíd y Claudine Legardinier (2006), Les clients de la prostitution, l'enquête, París: Presses De La Renaissance.

Bourdieu, Pierre (2000), La Dominación Masculina, Barcelona: Anagrama.

Butler, Judith (2001), "La cuestión de la transformación social”, en Beck-Gernsheim, E. et al., Mujeres y transformaciones sociales, Barcelona: El Roure.

Chodorow, Nancy J. (1989), Feminism and Psychoanalytic Theory, Cambridge: Polity Press and New Haven, Yale University Press.

Cobo, Rosa (2014), Informe proyecto investigación: consentimiento y coacción. Prostitución y politicas públicas (2010-2012), Madrid: Instituto de la Mujer.

Connell, Robert (2003), Masculinidades. Programa Universitario de Estudios de Género, México: Universidad Nacional Autónoma de México.

Díez Gutiérrez, Enrique Javier (2012), “El papel de los hombres en la prostitución...”, en Nuestra bandera: Revista de Debate Politico, núm. 232, Madrid: Partido Comunista de España, Nuestra Bandera.

Farley, M., Bindel, J. y J. M. Golding (2009), Men who buy sex, London: Eaves.

Federación de Mujeres Progresistas (2008), Trata de mujeres con fines de explotación sexual en España, Madrid.

García Ferrando, M. et al. (2000), El análisis de la realidad social: métodos y técnicas de investigación, Madrid: Alianza.

Gerhards, Jürgen (1995), Framingdimensions and framing strategies: contrasting ideal-and real-typeframes, London: Social Science Information.

Gilligan, Carol (1982), In a different voice, Harvard: University Press.

Gimeno, Beatriz (2012), La prostitución, Barcelona: Bellaterra.

Gilmore, David D. (1990), Manhood in the Making: Cultural Concepts of Masculinity, New Haven: Yale University Press.

Giusta, Marina Della, Di Tommaso, María Laura y Steirar Strom (2008), Sex Markets. A Denied Industry, London y New York: Routledge. 
Águeda Gómez-Suárez, Silvia Pérez-Freire y Rosa Ma Verdugo-Matés. Dominación, sexualidad masculina y prostitución en España: ¿por qué los hombres españoles consumen sexo de pago?

Goffman, Erving (1974), Frame analysis, Cambrigde: Harvard University Press.

Goldberg, S. (1973), The Inevitability of Patriarchy, New York: Willian Monrow and Company. Gómez, Águeda y Silvia Pérez (2009), Prostitución: clientes e outros homes, Vigo: Edicións Xerais.

Gómez, Âgueda et al. (2015), El putero español. Quiénes son y qué buscan los clientes de prostitución, Madrid: La Catarata.

Han, Byung-Chul (2014), La agonía del eros, Barcelona: Herder.

Irigaray, Luce (1998), Ser Dos, Buenos Aires: Paidós.

Jeffreys, Sheila (2011), La industria de la vagina. La economía politica de la comercialización global del sexo, Buenos Aires: Paidós.

López Insausti, Rafael y David Baringo Ezquerra (2007), "Ciudad y prostitución heterosexual en España: el punto de vista del 'cliente' masculino”, en Documentación Social, núm. 144, Madrid: Cáritas Española.

Manson, Sven-Axel (2001), "Men's practices in prostitution: the case of Sweden”, en Pease, Bob y Keith Pringle [comps.], A man's world?: changing men's practices in a globalized world, London, New York: Zed Books.

Marttila, Anne-Maria (2003), "Consuming sex: finish male clients and Russian and Baltic prostitution", 5a European Feminist Research Conference, Universidad de Lund, Suecia.

Meneses Falcón, Carmen (2010), "Factores motivacionales en una muestra de hombres españoles que pagan por servicios sexuales”, en Revista de la Asociación Española de Neuropsiquiatría, núm. 30, vol. 107, Madrid: Asociación Española de Neuropsiquiatría.

Miguel Álvarez, Ana de (2012), "La prostitución de mujeres, una escuela de desigualdad humana”, en Revista Europea de Derechos Fundamentales, núm. 19, Madrid.

Moore, Robert y Douglas Gillette (1993), The Magician Within: Accessing the Shaman in the Male Psyche, New York: William Morrow \& Company.

Nussbaum, Martha (1999), Sex and Social Justice, New York: Oxford University Press.

Otegui, Rosario (1999), "La construcción social de las masculinidades", en Politica y Sociedad, núm. 32, Lugar: Editora.

Ortnert, Sherry (1979), "Es la mujer al hombre lo que la naturaleza a la cultura?”, en Olivia Harris y Kate Young [comps.], Antropología y feminismo, Madrid: Anagrama.

Parsons, Talcott (1999), El sistema social, Madrid: Alianza.

Pasini, Elisiane (2000), “Límites simbólicos corporais na prostituçao feminina”, en Cadernos Pagu, núm. 14, Campinas: Universidade Estadual de Campinas.

Pateman, Carole (1988), "What is Wrong with Prostitution", en The Sexual Contract, Cambridge: Polity Press.

Preciado Ruiz, Beatriz (2002), Manifiesto Contra-Sexual, Madrid: Opera Prima.

Sáez, Hilario et al. (2015), Cómo somos los hombres. Masculinidades y prostitución en Andalucía, Sevilla: Fundación Iniciativa Social (inédito).

Sassen, Saskia (2003), Contrageografías de la globalización. Género y ciudadanía en los circuitos transfronterizos, Madrid: Traficantes de sueños.

Snow et al. (1993), "Framing proceses and identity construction in collective action", Paper presented at the Annual Meetings of the Midwest Sociological Society, Chicago, USA.

Solana Ruiz, José Luis (2002), "Prostitución de mujeres inmigrantes en la provincia de Córdoba”, en García Castaño, Francisco José et al. [coord.], La inmigración en España: contextos y alternativas, Granada: Universidad de Granada.

Tarrow, Sidney (1997), El poder en movimiento. Los movimientos sociales, la acción colectiva y la politica, Madrid: Alianza Universidad. 


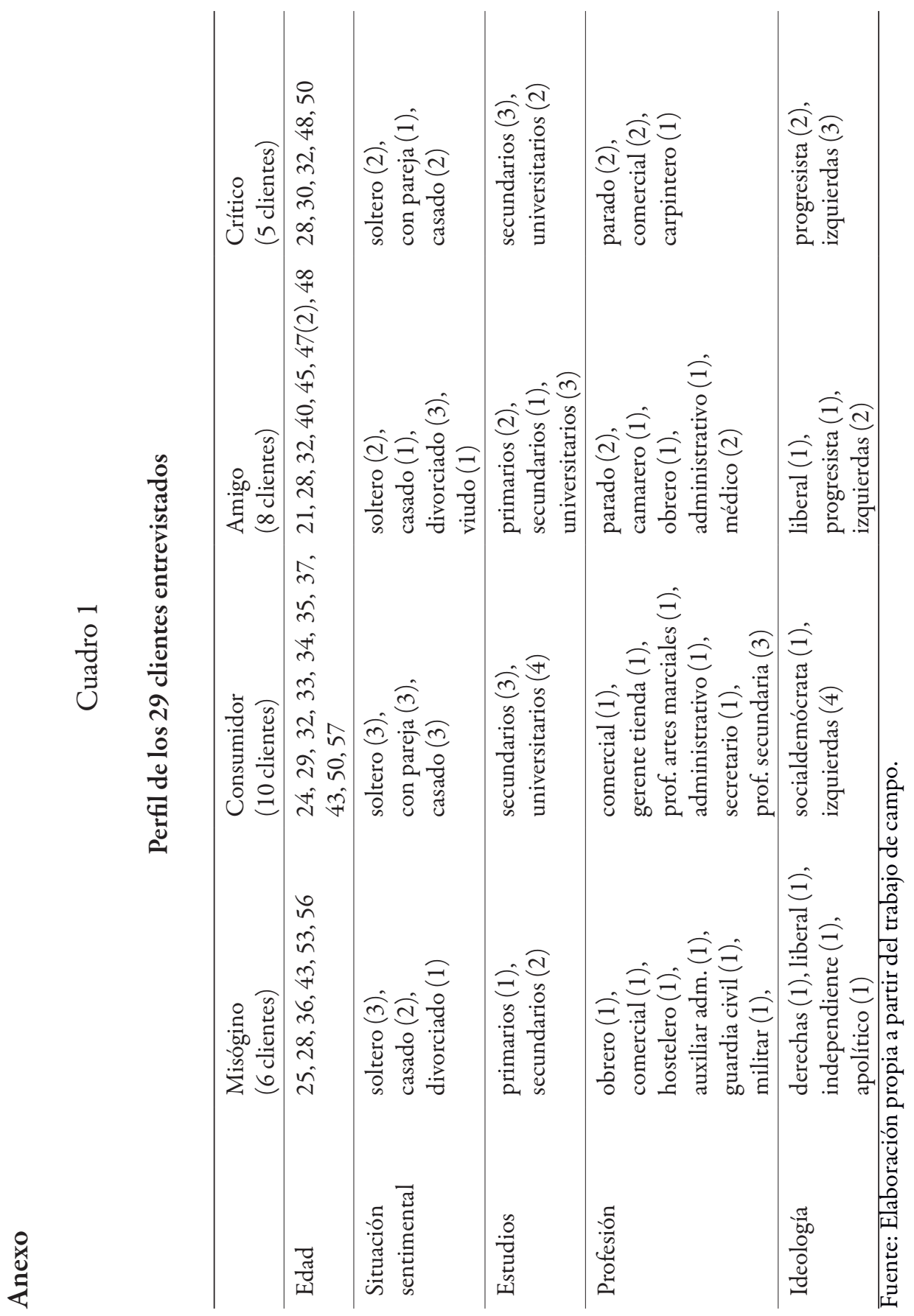


Águeda Gómez-Suárez, Silvia Pérez-Freire y Rosa Ma Verdugo-Matés. Dominación, sexualidad masculina y prostitución en España: ¿por qué los hombres españoles consumen sexo de pago?

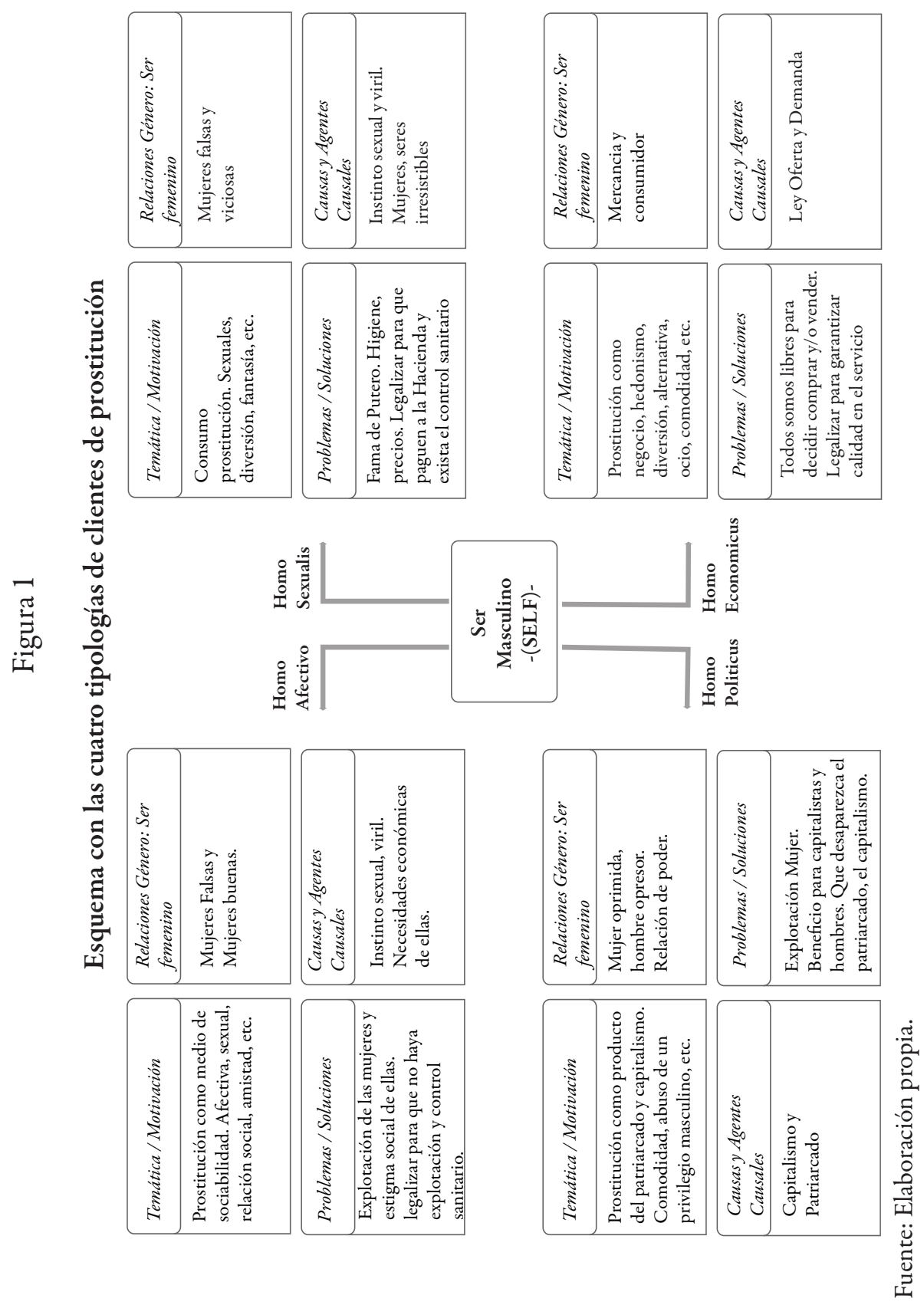


Águeda Gómez Suárez. Doctora en Sociología por la Universidad Complutense de Madrid. Es profesora en la Universidad de Vigo (España). Líneas de investigación: prostitución, sistemas sexo/género y etnicidad. Publicaciones recientes: Gómez Suárez, Águeda [coord.], Nuevas miradas sobre el género, la sexualidady la etnicidad, Santiago de Compostela: Andariva Editora (2013); Gómez Suárez, Águeda et al. [coords.], Diversidad sexual en Iberoamérica, Sevilla: Aconcagua (2013); Gómez Suárez, Águeda y Silvia Pérez Freire, Prostitución: clientes e outros homes, Vigo: Edicións Xerais (2009).

Silvia Pérez Freire. Licenciada en Sociología por la Universidad de A Coruña (España). Trabaja como socióloga e investigadora social especializada en Violencia de Género en ONG's vinculadas a la reivindicación de derechos humanos de las mujeres y como consultora científica en varias universidades españolas, empresas sociales y administración pública. Publicaciones recientes: Pérez Freire, Silvia et al. [coords.], A Trata con fins de explotación sexual, Santiago de Compostela: Secretaría Xeral de Igualdade (2013); Pérez Freire, Silvia et al. [coords.], Informe: Estudo Exploratorio da Trata de Persoas en Galicia, Santiago de Compostela: Xunta de Galicia (2013); Pérez Freire, Silvia et al., "Espejismos de igualdad. Consumo de prostitución femenina, masculinidades contemporáneas y etnicidad", en Gómez Suárez, Águeda [coord.], Nuevas Miradas sobre el Género, la Sexualidad y la Etnicidad, Santiago de Compostela: Andavira (2013).

Rosa Ma Verdugo Matés. Doctora en Ciencias Económicas y Empresariales por la Universidad de Santiago de Compostela. Centra sus investigaciones en las migraciones. Publicaciones recientes: Verdugo Matés, Rosa $\mathrm{M}^{\mathrm{a}}$ y $\mathrm{M}^{\mathrm{a}}$ José Piñeira Mantiñán, "Las remesas enviadas desde España: análisis de su impacto en las economía receptoras", en Boletín de la Asociación de Geógrafos Españoles, Madrid: Asociación de Geógrafos Españoles (2014); Verdugo Matés, Rosa $\mathrm{M}^{\mathrm{a}}$ et al., "Condicionantes de la actividad femenina en la Galicia de mediados del siglo XIX”, en Revista de Historia Industrial, Barcelona: Universitat de Barcelona (en prensa); Verdugo Matés, Rosa Ma, "Flux migratoires et économiques entre l'Europe et l'Afrique occidental", en R.C. Lois et al. [coords.], Planification et stratégies territoriales dans la société actuelle, Santiago de Compostela: AGALI (2013).

Recepción: 18 de abril de 2015.

Aprobación: 10 de febrero de 2016. 